\title{
RELATO DE CASO Deficiência de vitamina B12 e transtorno depressivo refratário
}

\author{
B12 deficiency and refractory depressive disorder: a case report \\ Bruno Cópio Fábregas', Flávia Domingues Vitorino', Antônio Lucio Teixeira`
}

\section{RESUMO}

A vitamina B12, ou cianocobalamina, desempenha importantes funções metabólicas e neurotróficas. Sua deficiência está associada a distúrbios hematológicos, neurológicos e psiquiátricos. É relatado o caso de uma paciente com depressão refratária ao tratamento com

\section{Palavras-chave}

Depressão, vitamina B12, tratamento, refratariedade.

\section{Keywords}

Depression, vitamin B12, treatment, refractoriness. antidepressivos que melhorou somente após a detecção e o tratamento da deficiência de vitamina B12. Esse relato ilustra a importância de o psiquiatra considerar causas secundárias de depressão em casos refratários.

\begin{abstract}
Vitamin B12, cyanocobalamin, is implicated in metabolic and neurotrophic functions. Its deficiency is associated with hematological, neurological and psychiatric disorders. Herein we report the case of a patient presenting with refractory depression who improved after the identification and treatment of vitamin B12 deficiency. This report highlights the relevance of considering secondary causes of depression in refractory cases.
\end{abstract}

\section{INTRODUÇÃO}

A vitamina B12, ou cianocobalamina, desempenha importantes funções metabólicas e neurotróficas no organismo. Pacientes com deficiência de B12 podem apresentar sintomas diversos como anemia megaloblástica, neuropatia periférica e sintomas psiquiátricos, especialmente transtornos depressivos ${ }^{1}$. É interessante notar que, segundo alguns trabalhos, níveis mais elevados de vitamina B12 estiveram associados a melhores resultados em pacientes com depressão maior tratados com antidepressivos².

Neste relato, descreveu-se o caso de uma paciente com transtorno depressivo refratário ao tratamento psicofarmacológico tradicional, que evoluiu com remissão dos sinto- mas depressivos logo após a correção de deficiência de vitamina B12.

\section{RELATO DE CASO}

Trata-se de paciente de 42 anos, do sexo feminino, solteira, sem filhos, católica, com primeiro grau completo, desempregada há cerca de seis meses, período em que interrompeu o trabalho que desempenhava como auxiliar de serviços gerais a fim de cuidar do pai que estava doente. A paciente solicitou ao seu clínico-geral um encaminhamento para acompanhamento psiquiátrico, pois persistia com sintomas depressivos a despeito do uso de amitriptilina na dose de $50 \mathrm{mg} / \mathrm{dia}$,

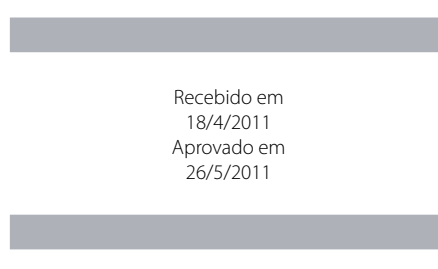

1 Universidade Federal de Minas Gerais (UFMG), Hospital das Clínicas, Serviço de Neurologia, Unidade de Neuropsiquiatria, Belo Horizonte, Brasil. 
prescrita pelo clínico há cerca de um ano, quando surgiram os primeiros sintomas. $\mathrm{Na}$ época da primeira consulta com o psiquiatra, a paciente residia com a mãe e com os dois irmãos, negando relacionamentos afetivos relevantes anteriormente.

$\mathrm{Na}$ avaliação psiquiátrica, a paciente queixou-se de insônia intermediária e despertar precoce, tristeza persistente, redução do apetite com emagrecimento (3 kg no último mês), além de falta de energia, anedonia e retraimento social. Ela apresentava humor deprimido, pensamento de menos-valia e desesperança, baixo volume de voz e lentificação psicomotora. Não exibia ideias delirantes e negava ideação suicida. Quando questionada sobre outros problemas de saúde, a paciente afirmava que fazia tratamento oftalmológico para glaucoma primário de ângulo aberto e que fazia uso de sulfato ferroso há um ano em virtude de anemia. Negou história pregressa e familiar de transtorno mental. O exame neurológico não revelou quaisquer sinais focais ou alterações sensitivo-motoras.

Considerando a hipótese de episódio depressivo maior, o psiquiatra adicionou à sua prescrição fluoxetina 20 mg/ dia, com progressão de dose até 40 mg/dia. Houve melhora parcial do humor e do apetite. A dose de amitriptilina foi aumentada gradativamente até $100 \mathrm{mg} / \mathrm{dia}$, mantendo-se essa dose por oito semanas. Como houve persistência dos sintomas depressivos, a fluoxetina foi substituída por paroxetina $25 \mathrm{mg} / \mathrm{dia}$, que foi usada por oito semanas, ainda associada à amitriptilina, mas sem melhora clínica.

Após cerca de um ano de tratamento psiquiátrico, outro psiquiatra passou a atender a paciente. Considerando a história clínica da paciente, marcada por depressão maior iniciada após os 40 anos de idade, refratariedade dos sintomas a diferentes antidepressivos e nova piora do apetite e consequente perda ponderal, o psiquiatra solicitou propedêutica laboratorial incluindo hemograma, glicemia de jejum, transaminases e função tireoidiana. O primeiro mostrou valores limítrofes para a série vermelha (3,73 milhões de hemácias, valor de referência: 3,8 a 5,2 milhões; 12,8 mg/dL de hemoglobina, valor de referência: 12 a 16 mg/dL; volume corpuscular médio no limite superior de $100 \mathrm{fL}$, valor de referência: 80 a 100 fL) e leucopenia (2.800 leucócitos, valor de referência: 4.000 a 11.000). Em seguida, foram solicitados ferritina e ferro séricos, dosagem sérica de ácido fólico e de vitamina B12 (cianocobalamina). Os exames estavam dentro da normalidade, exceto a vitamina B12, que estava bastante reduzida (41pg/mL, valor de referência: 200 a 900 pg/mL).

Foi prescrita, então, reposição vitamínica com administração intramuscular de vitamina B12. Optou-se por manter a prescrição de amitriptilina 100 mg/dia e paroxetina 25 mg/ dia. Três semanas após a primeira administração parenteral de vitamina B12, a paciente apresentou remissão completa dos sintomas depressivos. Uma endoscopia digestiva alta foi realizada, não evidenciando alterações no trato digestivo alto, incluindo gastrite atrófica, condição que acompanha a anemia perniciosa. Por meio de anamnese direcionada, evidenciou-se que a alimentação da paciente era pobre em fontes animais, afirmando não beber leite ou derivados e raramente ingerir carne vermelha. Nesse sentido, o psiquiatra realizou um aconselhamento dietético a fim de aumentar o aporte nutricional de vitamina B12. A paciente aderiu à proposta terapêutica, modificando seus hábitos alimentares gradualmente, não sendo necessária reposição da vitamina B12 além do tratamento inicial, que consistiu em quatro doses intramusculares de $5.000 \mathrm{UI}$. Os exames laboratoriais foram repetidos, havendo normalização dos níveis de vitamina B12 e do hemograma. A paciente evoluiu com eutimia em uso dos antidepressivos por mais seis meses, época em que os psicofármacos tiveram sua dose reduzida gradativamente até a suspensão completa. Não apresentou novo episódio depressivo ou de deficiência de vitamina B12 no seguimento de dois anos após a retirada dos antidepressivos.

\section{DISCUSSÃO}

Há na literatura relato de casos que apontam para a propriedade da vitamina B12 de reverter quadros depressivos com ou sem sintomas psicóticos ${ }^{3}$. No presente relato, o quadro depressivo, até então refratário ao tratamento com antidepressivos, respondeu ao uso parenteral de vitamina B12. A remissão dos sintomas ocorreu três semanas após o início da reposição de vitamina B12. Com efeito, os sintomas psiquiátricos associados à deficiência de vitamina B12 tendem a regredir após a administração terapêutica da vitamina em um período de uma a quatro semanas s.4. $^{3 .}$

A vitamina B12 é disponibilizada em alimentos, sendo sua absorção no íleo dependente da presença de fator intrínseco liberado pelas células parietais do estômago. Em humanos, a vitamina B12 é responsável por duas reações conhecidas: a conversão de ácido metilmalônico em succinil-coenzima $\mathrm{A}$ e a conversão de homocisteína em metionina. A deficiência de vitamina B12 poderia, portanto, levar a aumento de ácido metilmalônico e de metionina. Nos casos em que os valores de vitamina B12 se encontram próximos dos limites inferiores dos valores de referência, a dosagem de ácido metilmalônico e de homocisteína deve ser realizada, pois a elevação deles poderia indicar deficiência funcional de vitamina $\mathrm{B} 12^{5}$. Causas conhecidas de deficiência de vitamina B12 incluem: dieta deficiente na vitamina; má absorção por uso prolongado de inibidores da bomba de prótons ou de antagonistas histaminérgicos; ausência ou redução no fator intrínseco, como na anemia perniciosa e pós-gastrectomia, enterite ileal, doença de Crohn, ressecção ileal; deficiência de transcobalamina II (transportador responsável por via alternativa de absorção da vitamina) 6 .

Segundo a literatura, a dosagem sérica da vitamina B12 deveria ser realizada em pacientes com desnutrição, alcoo- 
lismo, cirurgia bariátrica e em pacientes com transtornos depressivos ou psicóticos refratários ao tratamento psicofarmacológico ${ }^{3}$. Além disso, a Academia Americana de Neurologia recomenda formalmente que pacientes com quadros demenciais sejam testados rotineiramente com dosagem sérica de vitamina $\mathrm{B} 12^{7}$. No caso, a iniciativa de dosar vitamina B12 se deveu a três fatores: primeiro, macrocitose no hemograma; segundo, hiporexia e perda de peso; terceiro, refratariedade ao tratamento com antidepressivos. Nesse sentido, vale ressaltar que nem sempre a deficiência de vitamina B12 é acompanhada de anemia ou macrocitose. Em um estudo envolvendo 141 pacientes consecutivos com transtornos neuropsiquiátricos associados à deficiência de vitamina B12, 40 deles (28\%) não apresentavam anemia ou macrocitose ${ }^{8}$.

Quando há necessidade de tratamento da deficiência de vitamina B12, pode-se optar por duas vias de administração da vitamina: oral, com doses diárias de 2.000 mcg por 120 dias; intramuscular, com injeções de 1.000 mcg 3x/semana, por duas semanas, seguidas de uma injeção mensal por mais três meses. Ambas vias de administração se mostraram eficazes na reposição da deficiência vitamínica?.

A propriedade da vitamina B12 e do ácido fólico de metilar moléculas precursoras de monoaminas como serotonina, noradrenalina e dopamina poderia explicar, ao menos em parte, a fisiopatologia dos transtornos do humor associados à sua deficiência. Além das monoaminas, a síntese da S-adenosil-metionina (SAM), responsável por várias reações de metilação no cérebro e com possíveis efeitos no humor, também depende da vitamina B12 e do ácido fólico ${ }^{10}$. Essas vitaminas funcionam como fontes do grupo metil, fundamental para a síntese de metionina a partir da homocisteína. A metionina, por sua vez, é a precursora imediata da SAM. Esta vem ganhando atenção dos pesquisadores no que se refere às suas propriedades antidepressivas. A SAM foi descoberta em 1952, tendo sido utilizada na Europa como antidepressivo, no final da década de 1970, e nos Estados Unidos, desde 1999, como suplemento dietético para condições como depressão e fibromialgia ${ }^{11}$. Estudos clínicos mostraram eficácia da SAM parenteral no tratamento de pacientes com depressão maior ${ }^{10}$. Algumas hipóteses foram levantadas para explicar a possível propriedade antidepressiva da SAM: a metilação de fosfolípides poderia alterar a permeabilidade e a atividade de membranas neuronais, interferindo nos receptores de monoaminas; a metilação do DNA celular poderia influenciar na sua transcrição; reações de metilação dependentes da SAM seriam necessárias para a síntese de neurotransmissores monoaminérgicos.

Não é rara a associação entre deficiência de vitamina B12 e deficiência de ácido fólico, e esta última condição também pode estar associada a sintomas psiquiátricos como alterações cognitivas e de humor ${ }^{12}$. A deficiência de ácido fólico também está associada a uma pior resposta ao tratamento de pacientes com depressão ${ }^{13}$, e o ácido fólico já demonstrou, em ensaios clínicos, efeitos terapêuticos no tratamento de pacientes com depressão ${ }^{14}$. Vale ressaltar que o ácido fólico administrado a pacientes com deficiência de vitamina B12 pode proporcionar efeitos adversos neurológicos quando a carência desta não é tratada concomitantemente ${ }^{12}$.

Em comparação com outras especialidades médicas, os psiquiatras dependem mais de entrevista e de exame clínico que de propedêutica complementar em sua prática. No entanto, em casos clínicos como o apresentado, a propedêutica laboratorial pode ser fundamental, contribuindo para o diagnóstico diferencial entre transtorno depressivo primário e secundário.

\section{REFERÊNCIAS}

1. Hvas AM, Nexo E. Diagnosis and treatment of vitamin B12 deficiency: an update. Haematologica. 2006;91(11):1506-12.

2. Hintikka J, Tolmunen T, Tanskanen A, Viinamaki H. High vitamin B12 level and good treatment outcome may be associated in major depressive disorder. BMC Psychiatry. 2003;3:17.

3. Hanna S, Lachover L, Rajarethinam RP. Vitamin b(12) deficiency and depression in the elderly: review and case report. Prim Care Companion J Clin Psychiatry. 2009;11(5):269-70.

4. Kate N, Grover S, Agarwal M. Does B12 deficiency lead to lack of treatment response to conventional antidepressants? Psychiatry (Edgmont). 2010;7(11):42-4.

5. Kaferle J, Strzoda CE. Evaluation of macrocytosis. Am Fam Physician. 2009;79(3):203-8.

6. Oh R, Brown DL. Vitamin B12 deficiency. Am Fam Physician. 2003;67(5):979-86.

7. Knopman DS, DeKosky ST, Cummings JL, Chui H, Corey-Bloom J, Relkin N, et al. Practice parameter: diagnosis of dementia (an evidence-based review). Report of the Quality Standards Subcommittee of the American Academy of Neurology. Neurology. 2001;56(9):1143-53.

8. Lindenbaum J, Healton EB, Savage DG, Brust JC, Garrett TJ, Podell ER, et al. Neuropsychiatric disorders caused by cobalamin deficiency in the absence of anemia or macrocytosis. 1988. Nutrition. 1995;11(2):181; discussion 0, 2.

9. Butler CC, Vidal-Alaball J, Cannings-John R, McCaddon A, Hood K, Papaioannou A, et al. Oral vitamin B12 versus intramuscular vitamin B12 for vitamin B12 deficiency: a systematic review of randomized controlled trials. Fam Pract. 2006;23(3):279-85.

10. Bottiglieri T, Laundy M, Crellin R, Toone BK, Carney MW, Reynolds EH. Homocysteine, foldte, methylation, and monoamine metabolism in depression. J Neurol Neurosurg Psychiatry. 2000;69(2):228-32.

11. Papakostas GI. Evidence for S-adenosyl-L-methionine (SAM-e) for the treatment of major depressive disorder. J Clin Psychiatry. 2009;70(Suppl 5):18-22.

12. Reynolds E. Vitamin B12, folic acid, and the nervous system. Lancet Neurol. 2006;5(11):949-60.

13. Papakostas GI, Petersen T, Lebowitz BD, Mischoulon D, Ryan JL, Nierenberg AA, et al. The relationship between serum folate, vitamin B12, and homocysteine levels in major depressive disorder and the timing of improvement with fluoxetine. Int J Neuropsychopharmacol. 2005;8(4):523-8

14. Coppen A, Bailey J. Enhancement of the antidepressant action of fluoxetine by folic acid: a randomised, placebo controlled trial. J Affect Disord. 2000;60(2):121-30. 